\title{
Thyroid Gland Leiomyoma
}

National Cancer Institute

\section{Source}

National Cancer Institute. Thyroid Gland Leiomyoma. NCI Thesaurus. Code C156346.

A leiomyoma that arises from the thyroid gland. 